\title{
Considerations Regarding Sustainable Development in the Vietnamese Coal Mining Industry
}

\author{
Naoko Shimazaki ${ }^{1}$ and Andre Xavier ${ }^{2 *}$ \\ ${ }^{1}$ Waseda University, Japan \\ ${ }^{2}$ University of British Columbia \& Canadian International Resources and Development Institute (CIRDI), Canada
}

\begin{abstract}
Over 10 million tourists have visited Vietnam in 2016. Travel and tourism accounted for 9.3\% of the country's Gross Domestic Product (GDP) in 2014. At the same time, as with many other resource-rich developing countries, Vietnam has been developing its extractive resources sector as a means of promoting the country's social and economic development. In 2015, mining was the third largest contributor to GDP, and accounted for $8 \%$ of Vietnam's gross domestic product. Vietnam is the third largest mineral producer in SE Asia. Although it produces zinc, nickel, bauxite, and manganese, coal mining is its most developed sector. The country has over two hundred coal mines, and total reserves of approximately 6 billion tons. Quang Nihn Province, where the World Heritage Site Ha Long Bay is located, is a very important tourism destination. It is also a coal-rich region where mining extraction and processing have been active since the early $20^{\text {th }}$ century. Vietnam is signatory of the United Nations Sustainable Development Goals (SDGs). The country is aware of the importance and the challenges involved in managing the extractive sector in a way that does not undermine its tourism industry and yet that contributes to the country's sustainable development. To this end Vietnam is taking actions towards implementing more advanced coal-mining extraction and processing techniques. The country is furthermore promoting a responsible mining sector, and is investing in programs that foster environmental protection and sustainable tourism. This paper examines the case of the Ha Long Bay region and the project involved in relocating the Hong Gai coal preparatory factory from a seafront area to a mountainside area. This paper provides a preliminary review of the initiatives adopted by the government of Vietnam to address the existing challenges that have resulted from a focus on promoting the country's socio-economic development through the exploration of its rich coal endowment. Furthermore, it also describes Vietnam's legal and policy frameworks. In conclusion this study identified that Vietnam has drafted a National Action Plan to implement the Sustainable Development Goals. The country is also taking an integrated approach to implementing the SDGs agenda and that it is assigning responsibility to a variety of ministries to achieve SDGs' specific targets. Furthermore the country is changing policies and the legal framework in order to facilitating the execution of the work of agencies that are responsible for implementation, regulation and enforcement. In this respect, the approval of the National Action Plan on Sustainable Development Goals is another important step in that direction. While the decision of supplying its internal market with high quality coal helps minimize negative environmental impacts in Vietnam, exporting low quality coal to other countries does not help resolve the problem of $\mathrm{CO}_{2}$ emissions globally. With respect to the 2030 Agenda, this may be considered a temporary solution since to achieve the SDG goals, Vietnam will have to consider other sources of cleaner energy in order to align with the Sustainable Development Goals \# 7 on affordable and clean energy.
\end{abstract}

Keywords: sustainable development, coal-mining, tourism, environment, responsible mining.

\section{Introduction}

Vietnam is known internationally for its tourism sector. Over 10 million tourists visited the country in 2016. Travel and tourism accounted for $9.3 \%$ of the country's GDP in 2014. At the same time, as with many resource-rich developing countries, Vietnam is seeking to develop its natural resources sector as a way of promoting the country's social and economic development.
The Vietnamese coal industry has a long history. In the post-Vietnam War era, the coal industry began to decline. However, in 1986, the government re-established this industry with the Doi Moi ${ }^{1}$ socio-economic plan. As well, in the 1990s, the Japanese government initiated one of its many technical assistance programs to support Vietnam's coal industry. This led to a steady increase in production which, after the year 2000, resulted in Vietnam expanding its exports, including to Japan. This production increase occasioned the need to increase the depth of its mines, which then required

${ }^{1}$ Doi Moi means 'renovation' and refers to the economic reform initiated in the country in 1986.

* Corresponding Author: A. Xavier, andre.xavier@ubc.ca

Copyright @ 2017 Canamaple Academia Services, http://press.camdemia.ca

DOI: 10.15273 /gree.2017.02.010 
Vietnam to begin modernizing its operations and coal-mining techniques. Today, Vietnam is the third largest mineral producer in Southeast Asia, and currently produces zinc, nickel, bauxite, coal and manganese. Coal is the country's most developed sector. There are 9 preparation facilities and over 200 coal mines, and Vietnam has total reserves of almost 6 billion tons (JOGMEG 2015). In 2015, mining was the third largest contributor to GDP, and had a high growth rate of $8.15 \%$ (JOGMEG 2016).

Government corporations have monopolized the Vietnamese coal industry for many years. From 1995 to 2011, VINACOAL was the primary government corporation running the industry, and this was more recently followed by the Vietnam National Coal and Mineral Industries Group (VINACOMIN). In 2016, VINACOMIN was made up of a conglomerate of 93 companies, and included 54 coal mines (30 underground operations), and it accounted for $95 \%$ Vietnam's coal production, representing 47 million tons per year. VINACOMIN currently employs over 134,000 people.

While benefiting economically from the development of its extractive sector, and in particular the coal sector, Vietnam is now faced with major environmental problems as listed below:

- Destruction of surface soil and vegetation has resulted from open pit mining. Noise and dust problems have also been a major issue.

- Drainage treatment. Waste from processing factories includes micro particulate mineral matter and powder coal, which cannot be disposed of directly into rivers. At present, there are more than thirty drainage facilities, and there will be 25 new facilities added by 2025 to the Quang Ninh Province Coal Field (JOGMEG 2013).

- Another major environmental problem relates to the recycling of slag heaps resulting from coal mining and processing factories. To save space, slag heaps are built up very high, resulting in risks of landslides. Greening technology faces several issues, for example dealing with steep-sided slag heaps, the greening of the slag yard, soil neutralization and the neutralization of drainage from slag heaps. VINACOMIN has asked Japan for technical assistance to resolve these issues, (JOGMEG 2013).

Since Ha Long Bay is in Quang Ninh Province, a World Heritage site recognized by UNESCO, VINACOMIN must produce coal while complying with both central and regional governmental environmental requirements. The unprecedented precipitation that fell upon the country in 2015 resulted in the flooding of five VINACOMIN operations, including one mine in the Ha Long Bay area. This flooding in particular caused concern regarding the contamination of the water bodies within the Heritage Site (ENDCOAL 2015).

In the face of these challenges, and committed to fostering its tourism sector and benefitting from a responsible coal industry, Vietnam is implementing measures to reduce the environmental footprint of its coal mines. These measures also are aligned with the country's commitment to the Sustainable Development Agenda. This paper provides an overview of the socio-economic development of the country, as well as the evolution of energy and coal policies in
Vietnam. It discusses the case of the Ha Long Bay coast, and the challenges of balancing coal production while fostering the tourism sector in the region. Finally, this paper also examines how Vietnam intends to implement its commitment to the Sustainable Development Goals. Specifically, it will look at the actions the country is taking to address the environmental challenges that have resulted from its coal sector, and how it intents to remain an attractive tourism destination while fulfilling its commitment to the 2030 Agenda.

\section{History of Vietnamese Socio-Economic Development}

Following the implementation of the Doi Moi development plan in 1986, the Vietnamese economic plan focused on the National Strategy for Socio-economic Development, a master plan that covered a period of ten years from 1991 to 2000 (JOGMEG 2015). In the following two decades, two other ten-year national plans were approved (Table 1). Over this period, the poverty rate in Vietnam dropped from 37.4 percent in 1998 to 8.4 percent in 2014 (JICA 2016).

\section{History of Vietnamese Coal and Energy Policies}

Vietnam has a series of policies and master plans in place to guide the coal and energy sector. The National Energy and Development Strategy (NEDS), ratified on December 27, 2007 describes Vietnam's energy policy to 2020 (Decision 1855/QD-TTg, NEDS). The Master Plan for Power Development for the period of 2011-2020 was approved in 2012 (Decision 1208/QD-TTg, PDP7), and the Master Plan on the Development of Vietnam's Coal Industry, also known as CDP60, with prospects towards 2030, was ratified in 2012 (No.60/QD-TTg, CDP60).

The CDP60 outlines the basic principles of coal industry development that include (JOGMEG 2016)

- To develop the coal industry while maintaining energy supply, and actively and efficiently contributing to the coal supply necessary for national socio-economic development.

- To encourage the development of a sustainable and efficient coal industry that is in line with the development of other industries.

- To promote and facilitate investment in the exploration of overseas coal mines.

- To ensure that the coal industry considers the conservation of the environment and that it contributes to nationwide socio-economic development.

In 2016, CDP60 was revised and two additional objectives were added (JCOAL Magazine (No.183, March 25, 2016)):

- The coal industry must be developed while considering the preservation of coal resources.

- Focus on the development of a coal industry that minimizes effects with respect to cultural preservation while maintaining the development of tourism.

This last point specifically speaks to the country's need to address the situation of the Ha Long Bay region, a growing tourism destination that has also been an important producer 
of coal, and that is responsible for $90 \%$ of the coal produced by VINACOMIN (Baresford et al 2004).

Table 1. Economic plan and results 1991-2020.

\begin{tabular}{ll}
\hline \multicolumn{1}{c}{ Plan } & \multicolumn{1}{c}{ Objectives and results } \\
\hline $1^{\text {st }}$ National & During this period, the government facilitated a \\
Strategy for & transition from a planned economy to a market- \\
Socio- & oriented economy. As a result, foreign \\
economic & investment increased, and the annual growth \\
Development & rate of GDP remained at around 8-9\% until the \\
(1991-2000) & Asian currency crisis in 1997. \\
& UN's HDI (Human Development Index) rapidly \\
& increased. For example, in 1990 its HDI was \\
& 0.44. In 1995 it was 0.49, ranking 122 out of 177 \\
& countries. This HDI score placed Vietnam in the \\
& "low human development" category, which is \\
& the last of four categories. However, by 1998 \\
& Vietnam entered the "medium human \\
& development" category, which is the third of the \\
& four categories (UNDP 1998). In 2014, \\
& Vietnam's HDI score was 116 out of 188 \\
& countries (UNDP 2015). \\
\hline Government facilitated industrialization and \\
Strategy for & modernization. \\
Socio- & The annual average GDP growth rate was \\
economic & 7.26\%, and the average GDP per person was \\
Development & US\$1,168. \\
(2001-2010) & Major problems developed regarding culture \\
& and environmental pollution. \\
& The quality of human resources, and the \\
society's infrastructure became limiting factors \\
for development. \\
The Vietnamese government introduced the \\
Environmental Conservation Law in 1994, and \\
it only took effect in 2006. \\
\end{tabular}

$3^{\text {rd }}$ National Strategy for

Socio-

economic

Development

(2011-2020)
Aims to make Vietnam a modernized industrialized country by 2020 .

The main goals are to increase GDP by $7-8 \%$ annually, and to achieve an average GDP per person of US\$3,000-3,200.

Aims to increase forested areas to $25 \%$ of national land.

Aims that whole population will have access to clean water by 2020 .

Goal is to attain an increase in GDP of up to $85 \%$ in the industrial and service sectors, and to reduce the rate of the agricultural population to $30 \%$. To achieve these goals, the government outlines three concrete strategies.

1. to establish market-oriented economic institutions that aspire to both socialism and competition, and to implement administrative reform.

2. to develop human resources, and to reform the education system.

3. to build adequate infrastructure, including modern buildings, and a modernized transportation system.

\section{The Ha Long Bay Area}

Ha Long Bay, located in the Gulf of Tonkin, within Quang Ninh Province in the northeast of Vietnam, is $165 \mathrm{~km}$ from the capital of Hanoi. It covers an area of 43,400 ha, and encompasses over 1600 islands. The area is also important because of its biodiversity. Ha Long Bay was established as a historical and cultural site, and classified as a National Landscape Site in 1962. Designated as a Special National Landscape Site under the Cultural Heritage Law that was amended in 2009, land tenure is held by Quang Ninh Province. The area is protected by several relevant provincial and national laws as well as governmental decrees including; the Cultural Heritage Law, the Bio-Diversity Law, the Tourism Law, the Environmental Protection Law, the Fishery Law, and the Marine Transport Law. Under these laws, any proposed action within the region that could have significant impact on the area must have official approval from the Ministry of Culture, Sports and Tourism, along with other relevant ministries (UNESCO 2017).

While the area has significant relevance for tourism and biodiversity, it is also an important coal extraction and processing area. In 1992, the Hon Gai Coal Preparation Factory began construction on the Ha Long Bay coast. It was completed in 1995, and began operation in 1996. Initially, it was made up of two factories, No.1 and No.2, and produced one million tons of clean coal annually. In 2001, it increased annual production to 2,600,000 tons. In 2010, the new factory, No.3, opened, and the total production increased to 3,400,000 tons annually, which at present produces an appropriate range of coal to meet market needs. The factory invested 13 million US dollars in improving its water recycling system, and the Japanese Kushiro Coal Mine Company provided important technical assistance.

In the Vietnamese coal industry, each mining company has a limited coal-processing infrastructure. Most raw coal is processed in separate preparation factories. In this context, Hon Gai buys raw coal from four coal mining companies, and produces eleven kinds of clean coal. In total, $77.8 \%$ of raw coal becomes clean coal, and the remainder is waste. The transportation of raw coal from the mining companies to the preparation factory is done by train, and the transportation of clean coal from the preparation factory to ships for export is done through conveyor belt.

The Ha Long Bay environment management committee was established in 2010, and the Project of Preservation of the Environment for Sustainable Tourism was approved. This project also considers the expansion of the Ha Long Bay urban area that is expected to be completed by the end of 2017.

Furthermore, according to this plan, it was established that the Hon Gai Coal preparation factory be relocated from its current location on the coast to a mountain site.

VINACOMIN is now facing with the challenge of relocating the Hon Gai facility.

As per the original plans, the relocation of the processing facility was planned to begin in 2015 and to be completed by 2016. However, as the company is still trying to secure an appropriate mountain site location, this plan has not yet been realized yet. The current plan is to complete the move by the 
end of 2018. After the closure of the existing factory, the land will be transferred from the company to the local government, and it is anticipated that the vacant site will be used for tourism, potentially to host an amusement park.

\section{Balancing Tourism and Coal Industries}

In consideration of the environmental challenges, as well as the country's commitment to improving the efficiency of the coal sector, promoting its tourism sector, and delivering on its commitment to the SDGs, a multipronged approach has been adopted.

- Vietnam is upgrading its coal processing facilities and is improving coal-processing technology with the goal of supplying its domestic market with high-quality grade and the export market with low-quality coal. This plan is behind schedule due to a decline in demand for coal.

- Vietnam plans to reduce its number of open pit mines from $55 \%$ in 2011 to $20 \%$ in 2030 , with the long-term goal of completely closing all open pit mines. To this end, the industry is transforming from open pit mining to underground mining. Reclamation and the replanting of former open pit mines has begun. This is particularly true for mines that are in the process of closing, as in the cases of Cao Son Mine and Ha Lam Mine. The afforestation program is supported by the Japan International Cooperation Agency (JICA).

- Seeking to secure appropriate financial resources, in 2006 , the government decided to assign a minimum of $1 \%$ of national expenditure to the environmental conservation budget.

- Vietnam is implementing more rigorous regulations to support the Environmental Conservation Law and the National Strategy for Environmental Conservation, which were approved in 2006, and which regulate water, air and wastage. As in the case of the Government Decree for Surcharges on Discharged Water (Decree No.67/ 2003/ ND-CP) and the Government Decision for Measures of Pollution Control in Case of Serious Contaminated Companies (Decision No.64/ 2003/ QD$\mathrm{TTg}$ ). Furthermore, in 2008 the government implemented the Government Decree for the Comprehensive Hydrographic Basin, Including Aquatic Conservation and Water Resource Control (Decree No.120/ 2008/ ND-CP).

In the case of Quang Ninh province where the Ha Long Bay Heritage Site is located, there seems to be a sense of urgency, and specific measures are being adopted. These measures, under the Project of Preservation of the Environment for Sustainable Tourism are:

- to enforce policy that supports sustainable tourism;

- to maintain a balance between the environment and development;

- to implement a public environmental education campaign;
- to monitor and investigate aquatic systems;

- to empower administrative offices to enforce regulations;

- to enforce a conservation fee of $6,000 \mathrm{don}^{2}$ per 1 ton of anthracite production, or 2,000 don per 1 ton of peat briquette production for the local province.

The transition from an open cast mine has already begun in the Ha Long Bay area. Ha Lam Mining, which is the largest company in Vietnam, is in the final phase of a transformation from open pit mining to underground mining. In 2008, it built a vertical shaft and started excavation, and in 2016 it started coal mining in the deepest coal seam. Its open pit will close in 2019. Ha Lam Mining is considered to be the most mechanized and safe coal mining company in Vietnam.

Furthermore, important measures to address drainage issues are being implemented to ensure that water quality is preserved in the Ha Long Bay. In the case of Ha Lam Mining, a full recycling system was put in place, and from December 25, 2016, the country's best system went into operation. Furthermore, the mine has also implemented mechanisms for the excretion of salt content, which is important in that the water salinity in the Ha Lam area is high.

As mentioned earlier, the redeployment of the coal preparation factory is another measure included in the Project of Preservation of the Environment for Sustainable Tourism. Due to local and central government demands, the Hong Gai Coal Preparation Company will move its factory from a seafront area to a mountainside area in 2018.

To comply with the request for relocation, the company must build a new area for coal storage. It also needs to build new drainage systems, and a water recycling system. The transportation of both raw and clean coal also become challenging, as the distance between the coal companies supplying the raw coal and the processing site will be longer. The distance between the processing facility and the port will also be increased, and the transportation of clean coal that is currently conducted by conveyor belt will have to be done by train.

\section{Vietnam and the UN Sustainable Development Goals}

In September 2015, 193 nations became signatories of the United Nations Sustainable Development Goals (SDG), committing to end poverty, protect the planet, and ensure prosperity for all. There are 17 SDG and 169 specific targets to be achieved by 2030 .

It is an ambitious project, and there is an expectation that government, civil society and the private sector will all play their parts in supporting the achievement of the goals.

The government of Vietnam is committed to contributing to the SDGs, and has been making efforts to effectively achieve the goals for the 2030 Agenda.

In this regard, the Vietnamese government has assigned the Ministry of Planning and Investment to lead the discussions and implement of the SDG Agenda. In November 2016, a consultative process began the development of a

\footnotetext{
${ }^{2}$ US $\$ 0.26$ per tone - (exchange rate March 28, 2017)
} 
National Action Plan (NAP) to implement the SDGs. The goal is that the Vietnam National Action Plan will provide a guidance framework, and help define activities and responsibilities for the country in order to implement the SDGs. "This national action plan will be the legal basis for Vietnam to fulfill its commitments to the international community, thus contributing responsibly to global efforts for sustainable development (UNDP 2016)."

The draft National Action Plan, which is expected to be approved in 2017, presents a phased approach to the implementation of the SDGs, and sets actions and defines responsibilities (UNDP 2016).

Between 2017-2020 Vietnam will:

- Improve its institutional framework and management system, as well as its legal system and policies, to support the implementation of the 2030 Agenda.

- Implement communication and education activities to raise public awareness of the SDGs, and NAP to implement the 2030 Agenda for the Sustainable Development.

- Develop indicators through which to monitor and evaluate results.Between 2021-2030 Vietnam will:

- Continue to monitor and evaluate results;

- As aligned with the SDGs, it will develop high-quality human resources in all fields to support the development of the country;

- Promote research in, and the application of science and technology, and transfer technology, in order to implement the SDGs;

Although the Ministry of Planning and Investment is responsible for the implementation of the SDGs, and is leading the development of the NAP, its responsibilities are shared with other ministries for the implementation of the NAP. The Ministry of Finance is expected to define the NAP budget, to implement the 2030 Agenda, and to develop policies to encourage all economic sectors, but the private sector in particular, to invest in implementing the SDGs. As well, the Ministry of Information and Communication is responsible for advocacy and raising public awareness. Furthermore, the NAP assigns 17 ministries and 4 Vietnamese agencies to take the lead in implementing the specific SDG targets.

\section{Conclusions}

This paper provides a preliminary desktop review regarding the initiatives adopted by the government of Vietnam to address the promotion of the country's socio-economic development by exploring its rich coal endowment.

It is anticipated that field research will take place and that one of the authors, and other members of the Japan Association for the Study of Former Coalfields (JAFCOF), will be able to report on the development of the Vietnamese plans as they relate to the relocation of the Hong Gai Coal Preparation Facility.

The current paper further describes Vietnam's policy frameworks and decisions, and some of the actions being implemented by the government to achieve its Sustainable
Development Goals. Based on the scope of the study, some concluding remarks are provided below.

It is promising that Vietnam is taking an integrated approach to implementing the SDGs agenda and that it is assigning responsibility to a variety of ministries to achieve specific targets. Meanwhile, it is also an interesting and sensible strategy that the government has put one ministry (the Ministry of Planning and Investment) in the place of major responsibility for the project.

Changing policies and the legal framework are fundamental to facilitating the execution of the work of agencies that are responsible for implementation, regulation and enforcement. In this respect, the approval of the National Action Plan on Sustainable Development Goals is another important step in that direction.

While supplying its internal market with high quality coal helps minimize negative environmental impacts in Vietnam, exporting low quality coal to other countries does not help resolve the problem of $\mathrm{CO} 2$ emissions globally. With respect to the 2030 Agenda, this may be considered a temporary solution since to achieve the SDG goals, Vietnam will have to consider other sources of cleaner energy in order to align with the Sustainable Development Goals \# 7 on affordable and clean energy.

Finally, following up on the Ha Long Bay case may provide important lessons globally since other countries may face similar constraints where mining activities take place in remote areas, and in cases where sensitive and complex environments exist.

\section{Acknowledgement}

This research project is supported by JSPS KAKENHI Grant Number 16K03793.

The authors would like to thank the reviewers for their comments and contribution to improve this paper.

\section{References}

Beresford, M., A.N. Tran and N.I.O.A. Studies, 2004. Reaching for the dream: Challenges of sustainable development in Vietnam. Institute Southeast Asian Studies, 36(3): 413 - 414.

ENDCOAL, 2015. The souring of Vietnam's coal dream. http://endcoal.org/2015/08/the-souring-of-vietnamscoal-dream/.

JICA, 2016. Press release. https://www.jica.go.jp/english/news/press/2016/160530 02.html.

JCOAL, 2016. JCOAL magazine. http://www.jcoal.or.jp/publication/magazine/upload/JM -183.pdf.

JOGMEG, 2013. World coal report. http://www.jcoal.or.jp/publication/wcr/worldcoalreport 6.pdf\#search=\%27World+Coal+Report+vol6\%27.

JOGMEG, 2015. Annual report http://coal.jogmec.go.jp/content/300315156.pdf\#search $=\% 27 \mathrm{JOGMEG}+2.6+\% \mathrm{E} 3 \% 83 \% 99 \% \mathrm{E} 3 \% 83 \% 88 \% \mathrm{E} 3$ $\% 83 \% 8 \mathrm{~A} \% \mathrm{E} 3 \% 83 \% \mathrm{~A} 0 \% 27$. 
JOGMEG, 2016. Annual report. UNDP, 2015. Human Development Report. http://coal.jogmec.go.jp/content/300315217.pdf.

UNESCO, 2017. Ha long bay.

http://whc.unesco.org/en/list/672. http://hdr.undp.org/sites/default/files/2015_human_dev elopment_report.pdf\#search=\%27UNDP+Human+Dev elopment+Report+2015\%27.

UNDP, 1998. Human development report http://hdr.undp.org/sites/default/files/reports/259/hdr_1 998_en_complete_nostats.pdf\#search=\%27UNDP+Hu man+Development+Report+1998\%27.

UNDP, 2016. Viet nam integrates sustainable development goals in national policy. http://www.vn.undp.org/content/vietnam/en/home/press center/pressreleases/2016/11/10/viet-nam-integratessustainable-development-goals-in-national-policy.html. 